\title{
A ESCUTA DOS PROFISSIONAIS COM SURDEZ INSERIDOS NAS ORGANIZAÇÕES: PELA AMPLITUDE DOS SENTIDOS NO MUNDO DO TRABALHO
}

\author{
Sheila Momi Coelho \\ Denise Macedo Ziliotto ${ }^{2}$ \\ Tainá de Oliveira ${ }^{3}$
}

\begin{abstract}
RESUMO
Este artigo analisa as experiências dos trabalhadores com surdez objetivando compreender as contingências enfrentadas por estes profissionais no contexto organizacional. A pesquisa, de característica qualitativa e descritiva, foi desenvolvida com 14 profissionais surdos que possuem vínculo empregatício, sendo a coleta de dados realizada através de questionários do Google Forms. Os resultados indicam possibilidades bastante restritas de comunicação nas organizações, reduzindo as oportunidades de relacionamento com os colegas pela ausência de tradutores de Libras e desconhecimento da língua de sinais. As possibilidades de reconhecimento e ascensão profissional para os participantes não se efetivam mesmo diante da capacitação técnica e aumento da escolaridade. A visibilidade das contingências vivenciadas pelos profissionais com surdez no trabalho pode contribuir para a qualificação inclusiva do âmbito organizacional enquanto espaço de pertencimento e participação social relevantes.
\end{abstract}

Palavras-chave: Inclusão. Lei das Cotas. Libras. Surdez.

\section{LISTENING TO DEAF WORKERS INSIDE ORGANIZATIONS: FOR A SENSES AMPLITUDE IN THE LABOR MARKET}

\begin{abstract}
This article analyzes the experiences of deaf workers in order to understand the contingencies faced by them in the organizational context. The research, with qualitative and descriptive characteristics, was developed with 14 deaf workers who have an employment relationship, and data collection was carried out through Google Forms questionnaires. The results indicate very limited possibilities of communication in organizations, reducing relationships opportunities due to the lack of Libras (Brazilian Sign Language) translators and lack of knowledge on sign language. The possibilities of recognition and professional advancement to the participants are not realized even if they have technical training and increased schooling. The contingencies visibility of deaf workers experience at work can contribute to the inclusive qualification on organizational scope as a relevant belonging place to social participation.
\end{abstract}

Keywords: Inclusion. Brazilian sign language. Quota Law.Deafness.

\footnotetext{
${ }^{1}$ Graduada em Gestão de Recursos Humanos pela Universidade La Salle. Email: smomi.rs@gmail.com

${ }^{2}$ Pós-Doutorado pela Universidade de Lisboa. Docente e pesquisadora no programa de Pós-Graduação em Educação da Universidade La Salle e no curso de Psicologia. Email: denise.ziliotto@unilasalle.edu.br Orcid: http://orcid.org/0000-0001-9146-5425

${ }^{3}$ Graduada em Psicologia pela Universidade La Salle. Email: taina.201810012@unilasalle.edu.br
} 


\title{
ESCUCHAR PROFESIONALES SORDOS EN LAS ORGANIZACIONES: PARA LA AMPLITUD DE LOS SENTIDOS EM EL MUNDO DEL TRABAJO
}

\begin{abstract}
RESUMEN
Este artículo analiza las experiencias de los trabajadores con sordera con el fin de comprender las contingencias que enfrentan estos profesionales en el contexto organizacional. La investigación, con características cualitativas y descriptivas, se desarrolló con 14 profesionales sordos que tienen relación laboral, y la recolección de datos se realizó a través de cuestionarios de Google Forms. Los resultados indican posibilidades de comunicación muy limitadas en las organizaciones, reduciendo las oportunidades de relacionarse con colegas debido a la falta de traductores de Libras y la falta de lenguaje de señas. Las posibilidades de reconocimiento y promoción profesional de los participantes no se realizan ni siquiera frente a la formación técnica y el aumento de la escolaridad. La visibilidad de las contingencias que viven los profesionales con sordera en el trabajo puede contribuir a la calificación inclusiva del ámbito organizacional como un espacio de participación y participación social relevante.

Palabras Llave: Inclúsion. Ley de cuotas. Libras. Sordera.
\end{abstract}

\section{INTRODUÇÃO}

Há algumas décadas o tema da inclusão tem sido discutido em diversas esferas da sociedade. Nesse contexto, buscando a garantia e a promoção dos direitos da pessoa com deficiência em condições de igualdade perante os demais em todos os sistemas sociais destaca-se a Lei Brasileira de Inclusão n 13.146/2015 (BRASIL, 2015). Entretanto, ainda há acesso restrito aos direitos - como no âmbito da educação e do trabalho - havendo a necessidade de que práticas sejam implementadas assegurando a efetividade da referida lei.

Conforme a Agência Brasil (2019) são 10,7 milhões de pessoas com alguma deficiência auditiva no Brasil, onde $9 \%$ já nasceram com esta condição. Pessoas na faixa dos 60 anos ou mais predominam esse público. Do total, 2,3 milhões possuem deficiência auditiva severa e 15\% destes, já nasceram surdos. No que tange ao mercado de trabalho, $43 \%$ dos deficientes auditivos com 18 anos ou mais estão empregados no setor privado e 37\% trabalhando como autônomos.

No que se refere à pessoa com deficiência, este estudo aborda especialmente sobre o profissional com surdez, buscando investigar quais são as contingências vivenciadas no contexto organizacional, a partir de sua inserção laboral e a inclusão efetiva desses sujeitos nas organizações. Para responder ao objetivo, foi desenvolvida pesquisa qualitativa descritiva com 14 profissionais, tendo como instrumentos de coleta de dados questionários do Google Forms, tendo sido os resultados posteriormente analisados na perspectiva da estatística descritiva e do conteúdo. 
Inicialmente serão apresentadas abordagens histórico-conceituais acerca do movimento social surdo no Brasil e sobre a inclusão no mundo no trabalho, questões que circunscrevem o campo analisado. Em seguida explicita-se o método que estruturou a investigação, bem como a apresentação dos elementos advindos da coleta de dados, seguida das considerações finais.

\section{O MOVIMENTO SOCIAL SURDO NO BRASIL}

É a partir da chegada ao Brasil do francês Hernest Huet, ex-diretor do Instituto de Surdos de Paris, que se inicia a história dos movimentos surdos no Brasil. As ações de Huet evidenciaram a importância da Língua de Sinais. Entre 1920 e 1930 foi fundada a Associação Brasileira de Surdos-Mudos, para lutar pelo direito da educação na sua língua natural e em busca da integração (KLEIN, 2005).

Nos anos 70, foi fundada a Federação Nacional de Educação e Integração do Deficiente Auditivo (FENEIDA). Em 1983, ocorreu o $3^{\circ}$ Encontro Nacional de Entidades de Pessoas Deficientes, em São Bernardo do Campo - SP. Nesse evento, foi organizada a Comissão de Luta pelos Direitos dos Surdos, grupo que ganhou força ao reivindicar, junto à FENEIDA, espaço para seu trabalho, reivindicação que foi negada naquela época. Os integrantes dessa comissão formaram uma chapa e venceram as eleições para diretoria da FENEIDA, sendo sua primeira ação a reestruturação do Estatuto da entidade, que passou a ser denominada Federação Nacional de Educação e Integração dos Surdos (FENEIS), em 1987. Essa mudança não se referiu apenas ao nome, mas a busca de uma nova perspectiva sobre os surdos (KLEIN, 2005). O objetivo da FENEIS é divulgar e informar a sociedade sobre "a capacidade profissional da pessoa surda e sua completa integração na sociedade como membro participante ativo, com seus direitos e deveres" (FENEIS, 1993, p. 7).

O movimento social surdo no Brasil se deriva dos movimentos sociais evidenciados especialmente na década de 80 - onde o país passava pelo processo de redemocratização e transformações significativas ocorriam a partir das fortes reivindicações de grupos excluídos, como os sujeitos com deficiência - somando possibilidades com a criação da Coordenadoria Nacional para Integração de Pessoas com Deficiência (CORDE) em 1986 (BRASIL, 1986).

No início, o movimento social surdo reivindicava o direito a contar com intérpretes para o uso da língua de sinais no atendimento das mais diversas áreas sociais, como instituições públicas e privadas, na saúde e na justiça. A a partir da década de 90 o movimento ganhou força, expandindo-se, estabilizando-se e redimensionando suas lutas em torno das reivindicações 
pertinentes à pessoa com surdez em defesa da oficialização da Libras como forma de comunicação, em igualdade de oportunidade com o sujeito ouvinte (BRITO, 2013).

A oficialização da Libras fortaleceu o movimento surdo, chegando ao Congresso Nacional, em 2002, com a promulgação da Lei de Oficialização da Libras em todo o território nacional. Os movimentos surdos empreendidos na metade dos anos 90 em diante, resultaram em mudanças na educação, entre elas, a formação de professores surdos e sua inserção nos espaços escolares (THOMA; KLEIN, 2010). Chaveiro et al (2014) mencionam que a língua de sinais é o traço de maior destaque cultural da comunidade surda. Ademais, é um sistema linguístico, parte constituinte desse sujeito, que agrega à cultura do povo e identidade surda.

Barros (2015) declara que o processo identitário da pessoa surda está relacionado com a sua comunidade, evidenciando também a importância do significado da denominação surdo e a língua de sinais como fator de pertencimento e vínculo com a cultura surda. De acordo com a visão nativista, a implicação no termo deficiente que está designada em deficiente auditivo, expressa a patologia da surdez. Entretanto, na concepção defendida nesta investigação, quando o sujeito se identifica como surdo está destacando uma diferença e não uma deficiência.

Gesser (2008) relata que, na sua trajetória de estudos e relação com pessoas da comunidade surda, percebeu que a defesa da utilização do termo surdo para alguns era a apresentação de outro discurso sobre a surdez e uma recusa às ideologias discursivas dominantes moldadas no oralismo. Assim, afirma que a narrativa e definição do surdo para a sociedade, na maioria ouvinte, está pautada em sua condição orgânica, e que estes o veem exclusivamente a partir dessa realidade. Consequência disto, o surdo e os códigos linguísticos que utilizam, tornam-se telas que deixam lacunas em aberto onde se projeta um preconceito cultural e um discurso sobre a "normalização" do indivíduo. Entretanto, Araújo (2005) salienta que não há limitações de cognição que sejam naturais da surdez, e sim possibilidades de oferta pelo grupo social que assegure o desenvolvimento desses sujeitos, em especial na área da linguagem e linguística.

\section{ACESSO AO TRABALHO: INSERÇÃO OU INCLUSÃO?}

Com o objetivo de promover a acesso das pessoas com deficiência ao mundo do trabalho a Lei n 813/91 (BRASIL, 1991) busca garantir a inserção dessas pessoas através de uma exigência legal. O artigo 93 trata da obrigação das empresas em contratar pessoas com deficiência proporcionalmente ao número de colaboradores que esta possua. Nesse contexto, Freitas (2012) argumenta sobre a necessidade de uma legislação especial para trabalhar o tema da surdez como diferença e não deficiência, a partir de ações como a acessibilidade à língua de sinais tanto para os surdos como para os ouvintes, partindo do pressuposto que a única barreira para essa situação é a 
FAZ CIÊNCIA, VOL. 23, N. 38, JUL/DEZ DE 2021 - P. 36 - 52

falta da língua falada. Além do cumprimento da obrigação legal por parte das empresas, para que a contratação das pessoas com deficiência no país ocorra de forma efetiva, é preciso em primeiro lugar - por parte dos gestores públicos e diretores organizacionais - uma superação de barreiras atitudinais e culturais para que seja possível a compreensão sobre as reais capacidades das pessoas com deficiência.

Santos; Vieira; Faria (2013) constataram em seus estudos que a contratação de pessoas com deficiência ocorre em número restrito de empresas, mesmo diante da declaração de organizações que assumem uma atitude de responsabilidade social e contratam antes mesmo de acontecer uma determinação legal. Todavia, outras contrataram por necessitarem e principalmente devido à obrigação de uma adequação a normas determinadas pelo Estado. Conforme Teodósio; Givisiéz (2003) os fundamentos essenciais na iniciativa de admitir pessoas com deficiência nas organizações reportam-se a uma atitude reativa às demandas legais e de opinião pública. A partir disto, o ingresso dos trabalhadores com deficiência nas empresas, ao invés de ter como resultado a inclusão social, acaba por gerar o aumento da discriminação e dificultar a integração dessa mãode-obra. Nesse contexto, a pretendida inclusão se transforma em simples inserção.

Santos; Vieira; Faria (2013) declaram não haver processos inclusivos efetivos para os surdos nas organizações, pois há inserção somente como resposta à exigência legal. Silva (2017) observa que, para assegurar o direito da pessoa surda ao trabalho, há necessidade de políticas que viabilizem não só o acesso, mas também a permanência destes profissionais no emprego, destacando o respeito às características deste grupo para não haver discriminação.

De acordo com Marin; Góes (2006) os empregadores resistem em contratar pessoas com surdez, havendo impedimentos para o trabalhador demonstrar suas habilidades. Quando conseguem ser contratados, encontram desafios na construção de relações interpessoais e na compreensão das dinâmicas do ambiente de trabalho. Santos; Vieira; Faria (2013) afirmam que, no ambiente organizacional, a relação entre surdos e ouvintes fica prejudicada pelos entraves no processo comunicacional, incluindo situações em que um intérprete deveria estar presente, como palestras e treinamentos realizados pela empresa. Borges Almeida, Siqueira e Sobrinho (2020) ao buscarem evidenciar os desafios do profissional surdo quando inseridos nas organizações e as práticas adotadas pelas empresas para recebê-los, declaram que não basta contratar, sendo necessária a sensibilização dos colaboradores, e assegurar posteriormente a igualdade de condições, exigências e reconhecimentos pertinentes. 
Segundo Viana e Irigaray (2016) alguns critérios - como o nível de instrução do candidato, para a admissão da pessoa com deficiência, incluindo o surdo - faz com que, em muitas situações, recaia sobre o próprio indivíduo a responsabilidade pela impossibilidade da ocupação em certos cargos na empresa. Araújo (2005) argumenta que para organizar uma prática de qualificação dos sujeitos surdos para o trabalho primeiramente deve-se garantir, no caso do Brasil, o acesso à Libras, o que possibilitará não só uma comunicação efetiva entre surdos e ouvintes que participam desse processo, mas também a significação, pelo surdo, dos elementos que fazem parte do trabalho para o qual se qualifica. O conhecimento da língua se faz necessário, tanto para os surdos, quanto para os ouvintes participantes da organização para que ações de inclusão efetivas sejam executadas. Quando tal condição não se estabelece, Borges et al (2020) avaliam o surdo se sente excluído e discriminado, havendo sofrimento por não conseguir se relacionar, podendo levar à demissão, configurando rotatividade nestas posições nas organizações.

Para Marin; Góes (2006) as restrições não estão relacionadas somente à comunicação, sendo o fator principal a falta de acesso à informação no ambiente de trabalho. Pode haver uma relação entre a ausência de interlocução e as demissões de colaboradores surdos, pois diante da incompreensão de normas e prerrogativas dos contratos e funcionamento das organizações podem ocorrer o não cumprimento de seus compromissos no trabalho, por muitas vezes entendidos como irresponsabilidade. Ao profissional surdo, assim como um ouvinte, são direcionadas exigências pertinentes ao contexto de trabalho; porém precisam ter acesso às informações e orientações relativas ao desempenho de suas atribuições, sendo importante salientar que a compreensão da dinâmica do trabalho, diante da restrita interlocução no ambiente laboral, não ocorre na mesma equidade entre surdos e ouvintes.

Outros fatores interferem para o alcance de uma inclusão efetiva: a falta de incentivos do governo para qualificar e inserir o surdo no mercado de trabalho (VIANA; IRIGARAY, 2016); a falta de treinamento, deixando por conta de colegas de trabalho o apoio aos colaboradores surdos (SILVA, 2017); a falta de intérpretes ou cursos que capacite para o uso da Libras viabilizando a comunicação entre pessoas com surdez e ouvintes na empresa (SANTOS; VIEIRA; FARIA, 2013).

Borges et al (2020) constataram, mediante entrevistas com trabalhadores surdos, que os desafios diários encontrados para estes sujeitos, estão relacionados à falta de apoio dos ouvintes e não na incapacidade destes para realização das atividades. Assim, para Viana; Irigaray (2016) indicam elementos a serem considerados pela empresa que se nomeia inclusiva: valorizar a diversidade humana observando as diferenças de cada um; fazer modificações essenciais na forma 
de administrar; implementar adaptações arquitetônicas; adequar instrumentos de trabalho e procedimentos e capacitar para a inclusão todos os recursos humanos.

\section{PERCURSO INVESTIGATIVO}

Esta pesquisa tem como objetivo investigar as experiências dos trabalhadores com surdez objetivando compreender as contingências enfrentadas por estes profissionais no contexto organizacional. Para responder ao intuito foi desenvolvida pesquisa qualitativa de característica descritiva, pois segundo Gil (2002), a pesquisa descritiva tem como objetivo principal a descrição das características de determinado grupo para levantar opiniões, atitudes e crenças da população.

O instrumento escolhido para a coleta de dados foi um questionário elaborado no Google Forms. Tal formulário é composto por sete perguntas fechadas e duas questões abertas. Cabe salientar que as perguntas foram formuladas e submetidas à análise de profissional intérprete de Libras para adequar a formulação à melhor compreensão do sujeito surdo. Os envios foram feitos via e-mail, para instituições representativas das pessoas surdas, intérpretes e tradutores de Libras, profissionais que trabalham para pessoas com surdez, e trabalhadores surdos, a partir da rede de contatos das pesquisadoras. Destes e-mails, foram obtidas 14 respostas, analisadas a seguir.

\section{OUVINDO O PROFISSIONAL SURDO}

Para a apresentação dos participantes e visando o anonimato, foi utilizada, no Quadro 1, a nomenclatura "P" para denominar os participantes. Predominantemente são moradores de Porto Alegre/RS, com idade média de 31 anos, escolaridade de ensino fundamental a superior completo. Distribuem-se de forma equitativa entre homens e mulheres e possuem áreas de atuação diversas: Área Administrativa (5), Analista de Processos (1), Desenvolvedor Jr (1), Designer Gráfico (1), Op. Fábrica e Setup (1), Op. de Produção (1), Processos Gerenciais (1), Professor (1), Professora de Libras (1) e UX Designer (1).

No que tange à escolaridade/qualificação profissional da pessoa surda a pesquisa revela que 11 dos respondentes possuem curso superior completo e incompleto. Ao correlacionarmos esses dados às declarações de 71,4\% dos participantes que afirmaram nunca terem sido promovidos nas empresas em que trabalharam, infere-se que a qualificação desses trabalhadores, por vezes, ainda é desconsiderada, tornando-se um desafio para seu desenvolvimento como profissional. Corrobora Silva (2017) afirmando que ao considerar a política de cotas como obrigatoriedade para as PCD é possível que nas vagas que são disponibilizadas para estes sujeitos 


\section{FAZ CIÊNCIA, VOL. 23, N. 38, JUL/DEZ DE 2021 - P. 36 - 52}

ainda desconsidere a qualificação que eles possuam, bem como a observância de plano de carreira para estes profissionais.

Quadro 1: Participantes da pesquisa

\begin{tabular}{|c|c|c|c|c|c|c|}
\hline & $\begin{array}{l}\text { Homem ou } \\
\text { Mulher }\end{array}$ & Idade & $\begin{array}{l}\text { Cidade e Estado } \\
\text { em que mora }\end{array}$ & Profissão & $\begin{array}{l}\text { Quanto } \quad \text { tempo } \\
\text { trabalha empresa } \\
\text { atual }\end{array}$ & Escolaridade \\
\hline P1 & Homem & 37 & Porto Alegre/RS & Analista de Processos & 1 ano & $\begin{array}{l}\text { Superior } \\
\text { Completo }\end{array}$ \\
\hline $\mathbf{P 2}$ & Mulher & 24 & Porto Alegre/RS & UX Designer & 9 meses & $\begin{array}{l}\text { Superior } \\
\text { Completo }\end{array}$ \\
\hline P3 & Mulher & 36 & Canoas/RS & Professora de Libras & $\begin{array}{l}\text { Prestação serviços } \\
\text { autônoma }\end{array}$ & $\begin{array}{l}\text { Superior } \\
\text { Completo }\end{array}$ \\
\hline P4 & Homem & 29 & Porto Alegre/RS & Desenvolvedor JR & 1 ano e meio & $\begin{array}{l}\text { Superior } \\
\text { Incompleto }\end{array}$ \\
\hline P5 & Homem & 27 & Porto Alegre/RS & $\begin{array}{l}\text { Operador Fábrica e } \\
\text { Setup }\end{array}$ & 8 anos & $\begin{array}{l}\text { Ensino Médio } \\
\text { Completo }\end{array}$ \\
\hline P6 & Mulher & 33 & $\begin{array}{l}\text { Ferraz de } \\
\text { Vasconcelos/SP }\end{array}$ & Administração & 9 anos & $\begin{array}{l}\text { Ensino Médio } \\
\text { Completo }\end{array}$ \\
\hline P7 & Homem & 34 & Porto Alegre/RS & Administrativo & 1 ano & $\begin{array}{l}\text { Superior } \\
\text { Incompleto }\end{array}$ \\
\hline P8 & Homem & 30 & Canoas/RS & $\begin{array}{l}\text { Assistente } \\
\text { Administrativo }\end{array}$ & 9 anos & $\begin{array}{l}\text { Superior } \\
\text { Incompleto }\end{array}$ \\
\hline P9 & Mulher & 30 & Porto Alegre/RS & $\begin{array}{l}\text { Assistente } \\
\text { Administrativa }\end{array}$ & 9 anos & $\begin{array}{l}\text { Superior } \\
\text { Completo }\end{array}$ \\
\hline P10 & Mulher & 31 & Porto Alegre/RS & $\begin{array}{l}\text { Assistente } \\
\text { Administrativo }\end{array}$ & 9 anos & $\begin{array}{l}\text { Superior } \\
\text { Completo }\end{array}$ \\
\hline P11 & Mulher & 29 & Porto Alegre/RS & Designer Gráfico & Não informou & $\begin{array}{l}\text { Superior } \\
\text { Completo }\end{array}$ \\
\hline P12 & Homem & 29 & Porto Alegre/RS & Processos Gerenciais & 6 anos & $\begin{array}{l}\text { Superior } \\
\text { Incompleto }\end{array}$ \\
\hline P13 & Mulher & 40 & Cachoeirinha/RS & Operador Produção & 9 anos & $\begin{array}{l}\text { Ensino Fund. } \\
\text { Completo }\end{array}$ \\
\hline P14 & Homem & 42 & Porto Alegre/RS & Professor & Não informou & $\begin{array}{l}\text { Superior } \\
\text { Completo }\end{array}$ \\
\hline
\end{tabular}

Fonte: Pesquisadoras

No que se refere à participação em atividades e capacitações na empresa, a maioria dos respondentes afirmaram que sempre são convidados. Nesse contexto, P6 declarou nem sempre contar a presença do intérprete de Libras nesses momentos e, somente 28,6\% dos respondentes declararam participar somente em alguns momentos destas ações. Dessa forma, P3 declara que 
participava e contava com a presença de intérprete de Libras na empresa em que trabalhou anteriormente no estado de São Paulo, mas em Porto Alegre nunca obteve tal apoio; P5 respondeu que em alguns momentos esquecem de chamar o intérprete, ficando em assistência para estes eventos; e ainda P8 declarou que a empresa oferta curso caso o colaborador tenha interesse em apropriar-se da Libras.

Evidencia-se, portanto, que - mesmo que a maioria tenha assinalado que sempre é convidada para atividades institucionais - é necessário assegurar a efetividade inclusiva das atividades, pois ante os $28,6 \%$ que responderam participar em alguns momentos, outros $28,6 \%$ responderam nunca terem integrado eventos ou capacitações nas empresas. Nesse sentido a LBI Lei Brasileira de Inclusão $n^{\circ}$ 13.146/15 (BRASIL, 2015) no seu art. $4^{\circ}$ assegura à pessoa com deficiência, em igualdade de oportunidade com os demais colaboradores, o direito a participar e o direito ao acesso aos cursos de capacitação, planos de carreira, promoções, bonificações e incentivos profissionais ofertados pela empresa. Dessa forma, infere-se que a reduzida acessibilidade das atividades propostas, bem como possíveis dificuldades no recebimento e compreensão das informações relativas à divulgação, constituem restrições para os trabalhadores surdos usufruírem de ações de desenvolvimento no âmbito organizacional.

No que concerne à Lei de Cotas no contexto empresarial, a pesquisa revela uma equalização entre os que a consideram muito importante $(35,7 \%)$ e os que a consideram nada importante (35,7\%). Corrobora Freitas (2012) argumenta que a lei implementada é uma forma de garantir o acesso do profissional com deficiência ao mercado de trabalho, sendo a principal porta de entrada para oportunidades para estes profissionais. Entretanto, Borges et al (2020) entendem que a lei não é garantia de inserção inclusiva e que haja reconhecimento de seu valor socioeconômico, configurando sua efetividade. Neste contexto, infere-se que as percepções dos participantes em relação à forma como avaliam a Lei de Cotas não é convergente, mas 28,6\% consideraram que "cotas" é importante, o que contabiliza 61,7\% de opiniões favoráveis. Assim sendo, a lei parece caracterizar sim uma oportunidade para os profissionais, como demonstrado no Gráfico 1, a seguir. 


\section{Gráfico 1: Importância Leis Cotas para a Inclusão Pessoa Surda}

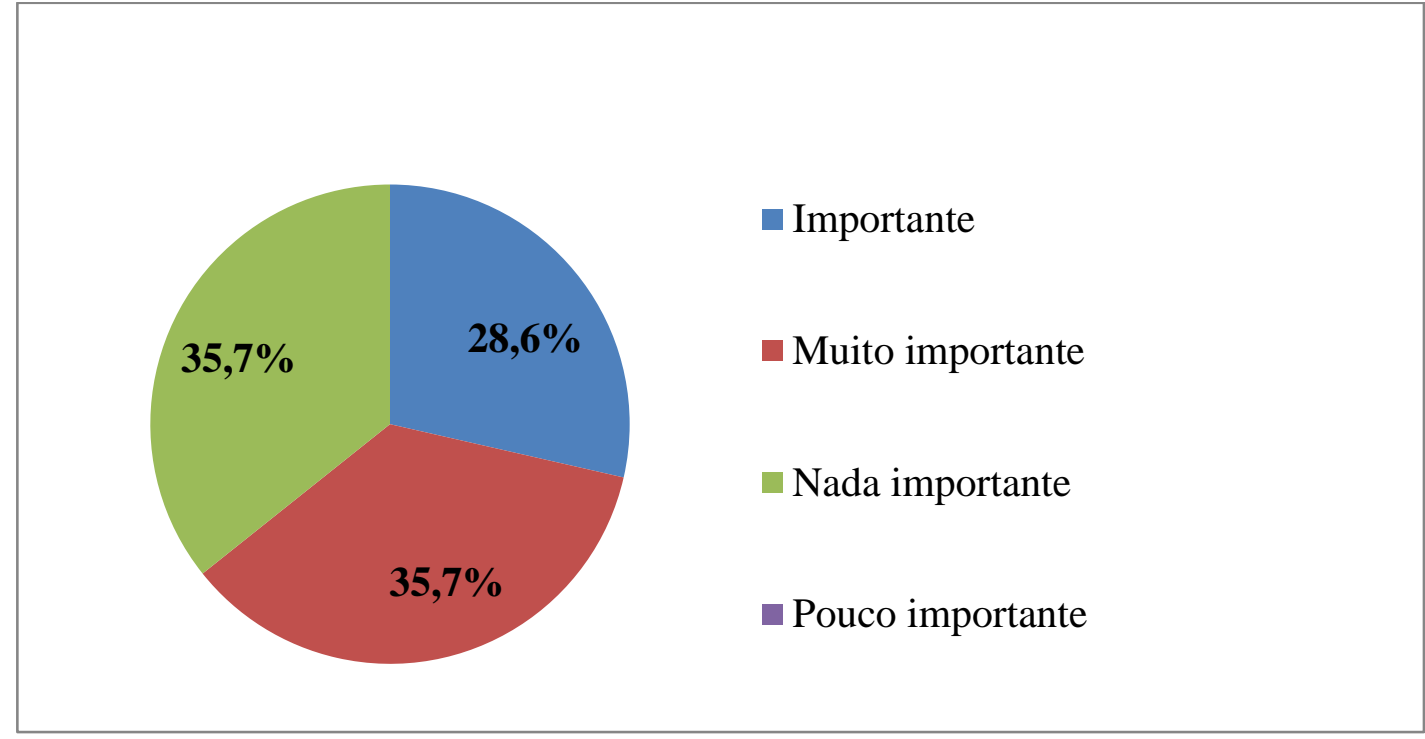

Um dado importante para orientar a análise é a informação quanto à oralização destes profissionais, sendo que apenas P6 (7,1\%) ter esta condição. Viana; Irigaray (2016) salientam que os empregadores têm preferência por pessoas com surdez que sejam oralizadas, evidenciando desrespeito pela língua destes sujeitos e reduzindo ainda mais as possibilidades de empregabilidade. Neste escopo, a pesquisa revela a partir dos dados apresentados que essa barreira não está totalmente transposta, mas se encaminha para ser erradicada.

Em relação à presença de intérprete de Libras no trabalho, 61,5\% dos participantes responderam que contam com este profissional somente em alguns momentos nas empresas, como em reuniões e eventos. Um ponto interessante a ser destacado é a declaração de um dos respondentes: "Tenho intérprete só que não é bem fluente em Libras" (P7), o que dimensiona as dificuldades de qualificação de interlocução existentes para os profissionais. A pesquisa revela que $23,1 \%$ sempre contam com este profissional no trabalho e $15,4 \%$ que nunca tiveram essa assistência. É importante salientar que a Lei $n^{\circ}$ 13.146/15 (BRASIL, 2015) no seu art. $73^{\circ}$ afirma que cabe ao poder público, de forma direta ou indireta (em parceria com a sociedade civil) promover a capacitação dos tradutores e intérpretes de Libras, de guias intérpretes e outros profissionais que possibilitem modalidades de comunicação acessíveis.

Ao identificar quais as formas de comunicação utilizadas pelo profissional surdo nas empresas, foram mencionadas: Libras $(85,7 \%)$, escrita $(78,6 \%)$, gestos $(50 \%)$ e leitura labial /escrita (42,9\%). Ao qualificarem estas modalidades de expressão, 71,4\% consideram a comunicação "mais ou menos", pois só os colegas de trabalho repassam as informações. Nesse sentido, identifica-se a necessidade de contar com o profissional Intérprete de Libras, em todos os 
momentos em que o profissional surdo estiver presente na organização, e/ou capacitar o quadro funcional para a Libras, garantindo a potencialidade efetiva da interlocução dos profissionais. Em consonância com este apontamento Silva (2017) declara que não havendo intérpretes no local de trabalho o profissional surdo fica prejudicado em seu desempenho, pela privação de orientações indispensáveis, que estão disponíveis aos ouvintes.

Referente à inclusão e como o profissional surdo se percebe nas empresas, as respostas, apresentadas no Gráfico 2, se diversificam quanto às percepções dos participantes. Uma parcela destes respondentes - 35,7\% declaram que se sentem incluídos, 50\% se sentem pouco incluídos e excluídos, e ainda $7,1 \%$ que se sentem pouco excluído, o que leva a inferir que mais da metade não se sente de fato incluído. Por outro lado, nenhum dos respondentes se declarou se sentir totalmente excluído e $7,1 \%$ consideram estar totalmente incluído.

\section{Gráfico 2: Avaliação dos profissionais quanto à inclusão}

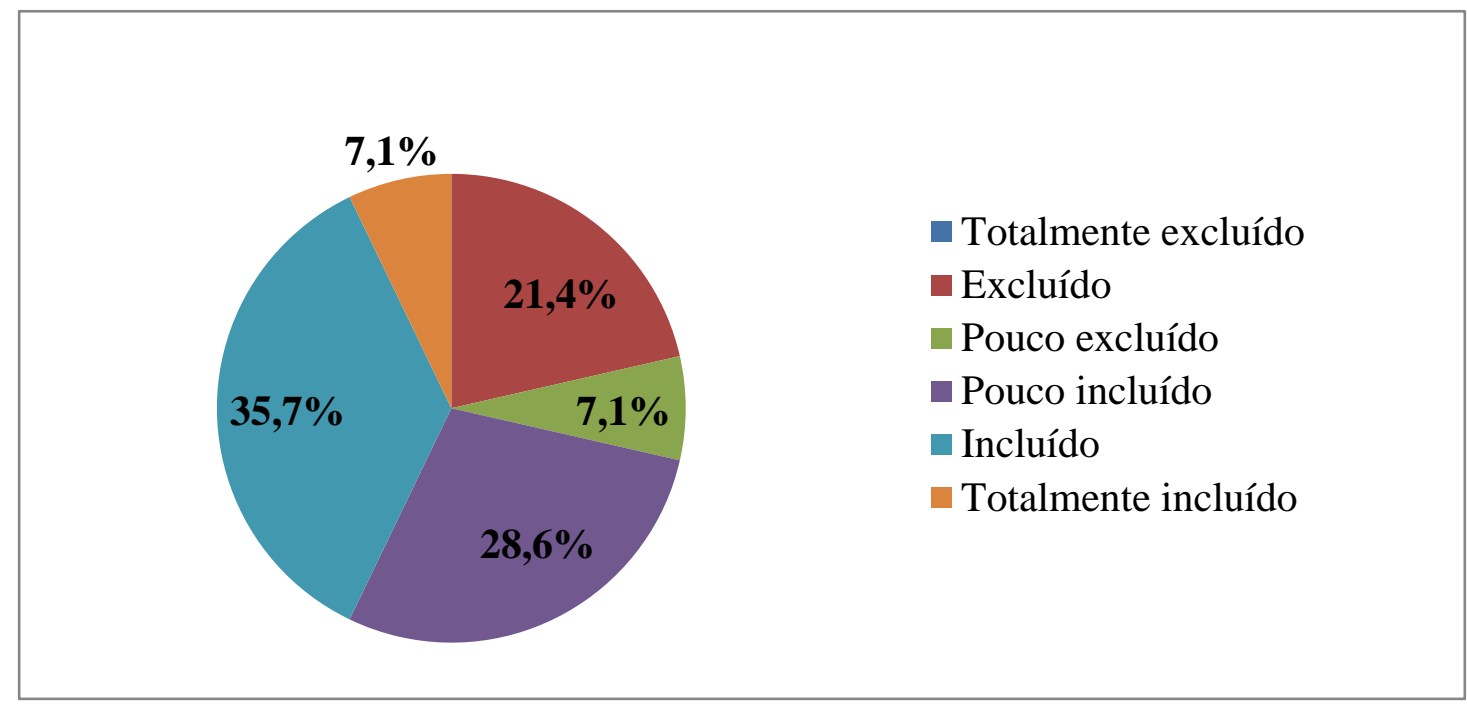

Em relação às dificuldades em seus atuais empregos ou anteriores, P1 e P8 assinalam a falta de comunicação, o que é enfatizado também por P6 “As pessoas não escrevem, boca difícil. Precisa falar claro aí PCDA entender as amigas. Precisa comunicação. ${ }^{4 ”}$ e P2, ao enfatizar que "Empregos anteriores são difíceis, pois colegas não sabem libras e não se esforçaram para se comunicar e não me deram as informações. Eu perdi muitas informações". Neste sentido, as informações corroboram o que Silva (2017) afirma ao declarar que os surdos percebem o processo lento de implementação da Libras como língua, dificultando o acesso em diversos âmbitos sociais,

\footnotetext{
${ }^{4}$ Mantivemos a expressão original das respostas dos participantes não realizando adaptações para a língua portuguesa.
} 
inclusive no trabalho. Ampliando o entendimento desta questão, $\mathrm{P} 4$ relatou a falta de acessibilidade no emprego anterior e P5 salienta a ausência de intérpretes ou colegas que saibam Libras, também se sentindo prejudicado por não ter informações. Conforme Freitas (2012), durante muito tempo a língua de sinais foi vista como uma forma de comunicação inferior, por se instituir a partir de gestos. Neste âmbito Graeff (2006) considera que a Libras, que utiliza o canal gestual-visual, é a melhor maneira para estabelecer uma boa comunicação entre ouvintes e pessoas com surdez, mas uma parcela dos coordenadores das equipes onde os trabalhadores com surdez se inserem não tem curso de Libras e não fizeram nenhum outro tipo de capacitação para trabalhar com pessoas com deficiência.

Ainda outra dificuldade identificada no âmbito organizacional é a falta de reconhecimento do profissional com surdez, identificada por P14 e presente na declaração de P3

Eu sou paulistana, morava em SP. Trabalhava na empresa, era maravilhosa como fosse segunda minha casa, porque tinha intérprete de Libras na empresa. Depois transferiu para cá em Poa, pensei: Igual empresa, mas não é. Percebi dentro empresa não tem intérprete. Quando chefe sempre me chamar para ir reunião com diretor, mas eu recusei com o chefe, porque não tem intérprete. Chefe me exigiu ir reunião, fui lá com chefe e colegas na sala de reunião com diretor da empresa. Quando começou falar, eu não entendi nada ele falando, me resolvi e levantei de pé na hora sair da porta. Direto fui do meu trabalho, continua trabalhar, chefe ficou brava comigo. Falei para ela não precisa ficar brava porque falta de respeito comigo, que não tem intérprete, nada. Depois anos, tempo, conseguiu outra empresa, mesma coisa igual sem o intérprete reunião, evento, etc. Me senti excluída, pois eu já pedi muitas vezes. Obrigar trazer intérprete de Libras é importante pra mim. O que aconteceu com reunião, e eventos.eu preciso saber isso. Mas empresa nunca respeita e nem ligou comigo, por isso (P3).

O relato demonstra como o respeito ao profissional com surdez o faz se sentir incluído. Também é possível perceber como profissionais em posição de liderança podem se posicionar gerando insatisfação, sofrimento e o sentimento de exclusão nos profissionais surdos.

Um ponto importante a destacar relativo às profissões de P3 e P14 é que ambos são professores. Tendo em vista que possuem a escolarização muitas vezes requerida, infere-se que para a inclusão dos profissionais surdos nas empresas não basta que estes sejam qualificados. Corrobora Marin; Góes (2006) sobre as considerações das dificuldades da pessoa surda, mostrando-se críticos quanto à forma como são tratados os trabalhadores surdos, evidenciando discriminações e falta de oportunidades. Outros participantes ainda declararam, relativo às dificuldades atinentes ao seu contexto profissional: que empresa anterior em Porto Alegre era horrível (P3); que todas as empresas são a mesma coisa (P7); já ter sido mais difícil anteriormente 
(P9); que às vezes é difícil (P12); que nunca foi difícil, mas quando é uma nova empresa começa difícil e depois acostuma (P11) e que antigamente era mais difícil de trabalhar e que agora está mais fácil (P13).

No que tange às ações das empresas para que o profissional surdo se sinta incluído, os participantes declararam a importância do profissional intérprete de Libras nas empresas, a comunicação com colegas e a aprendizagem de Libras: "É importante precisar respeito, união com surdos. O que precisa ter intérprete de Libras e também colegas podem aprender do curso de Libras para comunicação com surdos é mais importante. Os surdos podem satisfeita comunicação com colegas, sem barreiras" (P3). Também há declarações que enfatizam a relevância de inciativas de cunho motivacional (P1); empatia, boa vontade e sempre dar as informações (P2); união com colegas e ter vontade de aprender Libras, mas não sendo obrigatório (P5); mais oportunidades para aprendizagem e promoção (P6); maior facilidade para ser contratado nas empresas, por haver muita barreira nas vagas (P7); "Inclusão, igualdade e respeito" (P8); respeito pelo profissional surdo que precisa do trabalho para o sustento da família (P11) e desenvolver nível de igualdade (P14). Ainda houve a declaração de $\mathrm{P} 4$ que remete à compreensão de que as ações a serem implementadas dependerão da necessidade de cada profissional surdo.

Observa-se a necessidade de desenvolvimento de iniciativas e ações visando assegurar condições para o desenvolvimento profissional do trabalhador surdo, bem como assegurar a acessibilidade organizacional para comunicação entre todos os membros. Ademais, essa aproximação tornaria possível maior interação, empatia e respeito, descritas pelos participantes como sendo necessárias para que o trabalhador surdo se sinta incluído nas empresas. Neste sentido, destaca-se Borges et 1 (2020) ao constatarem que o desafio cotidiano para a pessoa surda não está na incapacidade de realizar algo, e sim na falta de apoio dos ouvintes.

A construção de uma sociedade que contemple as diferenças também precisa ser efetivada no mundo do trabalho. A existência de leis não assegura a mudança nas relações sociais, mas convoca a todos para a ampliação dos espaços de presença e exercício dos direitos pelos cidadãos com deficiência. A visibilidade das contingências vivenciadas pelos profissionais com surdez no trabalho pode contribuir para a qualificação do âmbito organizacional enquanto espaço de pertencimento e participação social relevantes. 


\section{CONSIDERAÇÕES FINAIS}

Este artigo abordou as experiências dos profissionais surdos no contexto organizacional a partir de pesquisa com 14 trabalhadores com objetivo compreender as contingências enfrentadas pelos trabalhadores no contexto organizacional. A pesquisa é qualitativa e o delineamento descritivo, tendo como instrumento de coleta de dados questionários do Google Forms.

Primeiramente observa-se a barreira atitudinal da comunicação entre surdos e ouvintes. Mesmo que os profissionais com surdez tenham relatado que se utilizam de diversas formas para se comunicar na empresa - intérprete de Libras, escrita, gestos, leitura labial - é perceptível que essa comunicação não é efetiva, pois os participantes identificam dificuldades no relacionamento com os colegas. Outro aspecto importante indicado é a falta de atenção dos empregadores para contratarem intérpretes de Libras para acompanharem os trabalhadores em toda a sua interação na empresa ou capacitarem colegas para essa mediação, não restringindo às situações eventuais como reuniões, eventos ou capacitações.

Mesmo que os trabalhadores participantes da pesquisa possuam curso superior completo (50\%) ou incompleto $(28,6 \%)$, evidenciando qualificação técnica, não se evidenciam oportunidades de crescimento e promoção para os profissionais. Os trabalhadores percebem a obrigatoriedade das cotas nas empresas como uma política de oportunidades para a contratação dos profissionais com deficiência, mas 35,7\% dos participantes não consideram esta política importante, questionando se a política é inclusiva.

Diante dos resultados fica evidente a existência de dificuldades significativas para a consolidação do contexto organizacional como ambiente inclusivo para profissionais com surdez. A visibilidade das contingências identificadas pela pesquisa pode contribuir para a qualificação inclusiva do âmbito organizacional enquanto espaço de pertencimento e participação social relevantes. 


\section{REFERÊNCIAS}

AGÊNCIA BRASIL. País tem 10,7 milhões de pessoas com deficiência auditiva, diz estudo. Agência Brasil, 2019. Disponível em: <https://agenciabrasil.ebc.com.br/geral/noticia/201910/brasil-tem-107-milhoes-de-deficientes-auditivos-diz-estudo〉. Acesso em: 05 jul. 2020.

BARROS, Eudenia Magalhães. Ações Coletivas, Identidade e Mobilizações Políticas: Movimento Social Surdo E A Luta Por Reconhecimento. 2015. Dissertação (Mestrado em Sociologia) - Universidade Estadual de Campinas, Instituto de Filosofia e Ciências Humanas, Campinas, SP, 2015. Disponível em: $<$ http://repositorio.unicamp.br/jspui/bitstream/REPOSIP/279622/1/Barros_EudeniaMagalhaes M.pdf>.

BORGES, Rosangela Lopes et al. Inserção e Permanência de Surdos no Mundo do Trabalho: Estudo Exploratório em Empresas de Um Município do Centro-Oeste Goiano. Revista Educação Artes e Inclusão, v. 16, n. 1, Florianópolis, SC, mar 2020. Disponível em: $\langle$ http://revistas.udesc.br/index.php/arteinclusao/article/view/14429/pdf $>$.

BRASIL. Lei $n^{\circ}$ 13.146, de 6 de julho de 2015. Institui a Lei Brasileira de Inclusão da Pessoa com Deficiência (Estatuto da Pessoa com Deficiência), Brasília, DF, jul 2015. Disponível em: 〈http://www.planalto.gov.br/ccivil_03/_ato2015-2018/2015/lei/113146.htm〉. Acesso em 05 de julho de 2020.

BRASIL. Lei $n^{\circ}$ 8.213, de 24 de julho de 1991. Dispõe sobre os Planos de Benefícios da Previdência Social e dá outras providências, Brasília, DF, jul 1991. Disponível em: <http://www.planalto.gov.br/Ccivil_03/LEIS/L8213cons.htm〉. Acesso em 05 de abril de 2020.

BRASIL. Decreto $n^{\circ} 93.481$, de 29 de outubro de 1986. Revogado pelo Decreto $\mathrm{n}^{\circ} 3.298$, de 20 de dezembro de 1999. Regulamenta a Lei ${ }^{\circ} 7.853$, de 24 de outubro de 1989, dispõe sobre a Política Nacional para a Integração da Pessoa Portadora de Deficiência, consolida as normas de proteção, e dá outras providências, Brasília, DF, dez 1999. Disponível em: 〈http://www.planalto.gov.br/ccivil_03/decreto/D3298.htm\#art60 > . Acesso em: 16 de maio de 2020.

BRITO, Fabio Bezerra. O movimento social surdo e a campanha pela oficialização da língua brasileira de sinais. 2013. 275 f. Tese (Doutorado em Educação) - Faculdade de Educação Universidade de São Paulo, São Paulo, 2013. Disponível em:

$<$ https://teses.usp.br/teses/disponiveis/48/48134/tde-03122013133156/publico/FABIO_BEZERRA_DE_BRITO.pdf>.

CHAVEIRO, Neuma et al. Qualidade de vida dos surdos que se comunicam pela língua de sinais: revisão integrativa. Interface (Botucatu), Botucatu , v. 18, n. 48, p. 101-114, 2014. Disponível em: <http://www.scielo.br/scielo.php?script=sci_arttext\&pid=P1414-

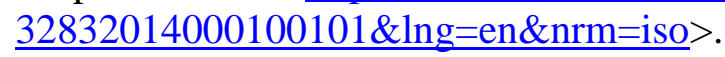

FENEIS - Federação Nacional de Educação e Integração dos Surdos. Relatório Anual: 1993. Rio de Janeiro: FENEIS, 1993. 
FREITAS, Francisca Muldiane Pedrosa. A Inclusão do Surdo no Mercado de Trabalho. 2012. 154 f. Dissertação (Mestrado Acadêmico ou Profissional em XX) - Universidade Estadual do Ceará, 2012. Disponível em:

<http://siduece.uece.br/siduece/trabalhoAcademicoPublico.jsf?id=75062>.

GESSER, Audrei. Do patológico ao cultural na surdez: para além de um e de outro ou para uma reflexão crítica dos paradigmas. Trab. linguist. apl., v. 47, n. 1, p. 223-239, Campinas, Jun 2008. Disponível em: <https://www.scielo.br/scielo.php?script=sci_arttext\&pid=S0103$18132008000100013 \& \operatorname{lng}=\mathrm{pt} \& \ln \mathrm{l}=\mathrm{pt}>$.

GRAEFF, Talita Diane. A relação do surdo com o mercado de trabalho. Revista Conexão UEPG, v.2 (1), pp. 23-28, 2006. Disponível em:

<https://www.revistaP2.uepg.br/index.php/conexao/article/view/3848/2724>.

KLEIN, Madalena. Movimentos surdos e os discursos sobre surdez, educação e trabalho: a constituição do surdo trabalhador. Universidade Federal do Rio Grande do Sul. Porto Alegre, 2005. Disponível em: <https://cultura-sorda.org/movimentos-surdos-constituicao-do-surdotrabalhador/\#: :text=do\%20surdo\%20trabalhador-

,Movimentos $\% 20$ surdos $\% 20 \mathrm{e} \% 20 \mathrm{os} \% 20$ discursos $\% 20$ sobre $\% 20$ surdez $\% 2 \mathrm{C} \% 20$ educa $\% \mathrm{C} 3 \% \mathrm{~A} 7$ \%C3\%A3o\%20e\%20trabalho,Porto\%20Alegre\%2C\%202005.\&text=Mas\%20as\%20quest\%C3 \%B5es\%20discutidas\%20pelos,suas\%20realidades\%20locais\%20e\%20nacionais. $>$.

MARIN, Carla Regina; GÓES, Maria Cecilia Rafael. A experiência de pessoas surdas em esferas de atividade do cotidiano. Cad. CEDES, v. 26, n. 69,p. 231-249, Campinas, ago 2006.

Disponível em: <https://www.scielo.br/scielo.php?script=sci_arttext\&pid=S0101-

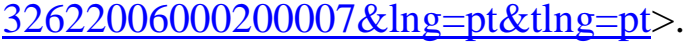

SANTOS, Thalita Mara; VIEIRA, Lidia Cristiane; FARIA, Cleyciane Alves. Deficiência auditiva e mercado de trabalho: uma visão de empregadores da cidade de Uberlândia - MG. Psicol. teor. prat., v.15, n.2,p. 92-103, São Paulo, ago 2013. Disponível em:

$<$ http://pepsic.bvsalud.org/scielo.php?script=sci_arttext\&pid=P1516$\underline{36872013000200007 \& \operatorname{lng}=\text { en \&tlng=en> }}$.

SILVA, Larissa Jorge. O surdo e o direito ao trabalho: para além do acesso. 2017. Dissertação (Mestrado em Desenvolvimento, Tecnologias e Sociedade) - Programa de pós-graduação em Desenvolvimento, Tecnologias e Sociedade, Universidade Federal de Itajubá, 2017. Disponível em:

<https://repositorio.unifei.edu.br/xmlui/bitstream/handle/123456789/805/dissertacao_silva4_201 7.pdf? sequence $=1 \&$ is Allowed $=\mathrm{y}>$.

TEODÓSIO, Armindo dos Santos de Sousa; GIVISIÉZ, Lucas José Boas. Estratégias corporativas para a inclusão de portadores de deficiência no trabalho. Revista de Administração da UNIMEP, v. 1, n. 1, p. 1-12, 2003. Disponível em:

$<$ http://www.spell.org.br/documentos/ver/26673/estrategias-corporativas-para-a-inclusao-deportadores-de-deficiencia-no-trabalho/i/pt-br>. 
THOMA, Adriana da Silva; KLEIN, Madalena. Experiências educacionais, movimentos e lutas surdas como condições de possibilidade para uma educação de surdos no Brasil. Cadernos de Educação - Faculdade de Educação | UFPEL. Pelotas, maio/agosto 2010. Disponível em: <https://periodicos.ufpel.edu.br/ojs2/index.php/caduc/article/view/1603/1486>.

VIANA, Alvanei dos Santos; IRIGARAY, Helio Arthur Reis. A Inserção dos Surdos no Mercado de Trabalho: Políticas Públicas, Práticas Organizacionais e Realidades Subjetivas. Revista Gestão e Planejamento, Salvador, v. 17, n. 2, p. 214-232, ago 2016. Disponível em: <https://revistas.unifacs.br/index.php/rgb/article/view/4169/2905>. 